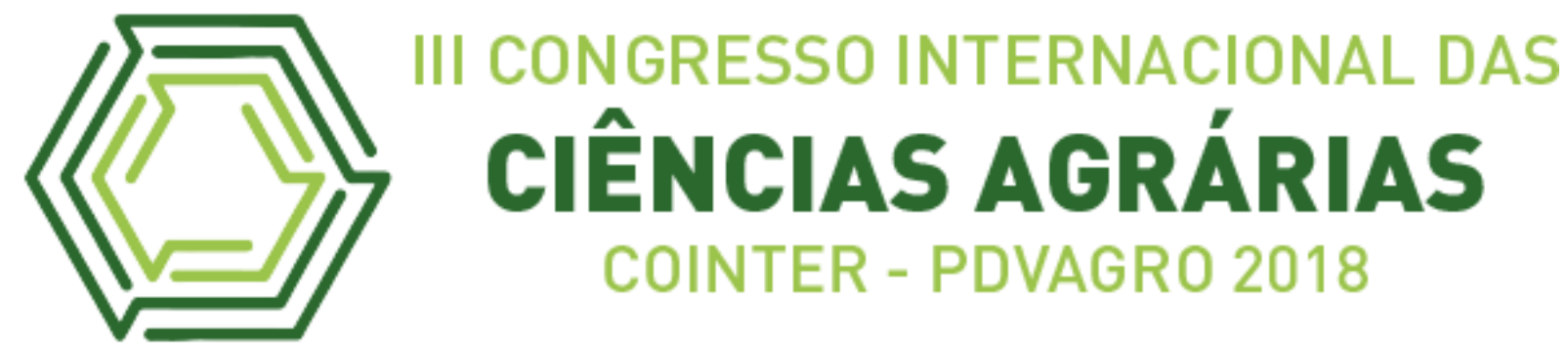

\title{
EFEITO DA APLICAÇÃO DO GEL HIDRORRETENTOR SOBRE A SOBREVIVÊNCIA DE MUDAS DE Eucalyptus grandis AOS CINCO E TRINTA DIAS PÓS-PLANTIO
}

\section{EFFECT OF THE APPLICATION OF HYDRORETHETER GEL ON THE SURVIVAL OF Eucalyptus grandis seedlings IN THE FIVE AND THIRTY POST- PLANTIO DAYS}

\author{
Jayne Sousa Antunes ${ }^{1}$; Fernando Almeida da Conceição ${ }^{2}$; Jossimara Ferreira \\ Damascena ${ }^{3}$; Diego Freire Almeida ${ }^{4}$; Wilson Araújo da Silva ${ }^{5}$ \\ DOI: https://doi.org/10.31692/2526-7701.IIICOINTERPDVAGRO.2018.00440
}

\section{Introdução}

O setor florestal brasileiro conta com, aproximadamente, 530 milhões de hectares de florestas nativas, 43,5 milhões de hectares em unidades de conservação federal e 4,8 milhões de hectares de florestas plantadas, nas quais se destaca o eucalipto (Eucalyptus spp.) (MEDRADO, 2003).

As deficiências hídricas e nutricionais estão entre os principais fatores que limitam a produtividade das culturas em solos agrícolas em várias partes do mundo (FAGERIA, 1989). $\mathrm{O}$ uso de gel hidrorretentor $(\mathrm{GH})$ no plantio de eucalipto tem como objetivo reter água próximo às raízes das mudas, reduzindo a necessidade de irrigação e melhorando a viabilidade das mudas, principalmente com plantio em períodos ou regiões de seca (estiagem).

Com o gel, a muda de eucalipto fica úmida no período mais crítico do desenvolvimento da planta. Isso elimina a exigência de irrigação imediata. Dependendo da condição do solo, a planta pode ficar de oito a quinze dias sem irrigação. Na média, o consumo de água cai de 6,5 litros por muda para 2,6 litros. Reduzindo o nível de mortalidade

\footnotetext{
${ }^{1}$ Engenharia Florestal, Universidade Estadual da Região Tocantina do Maranhão, jaynesousa98@gmail.com

${ }^{2}$ Engenharia Florestal, Universidade Estadual da Região Tocantina do Maranhão, feernando86@gmail.com

${ }^{3}$ Engenharia Agronômica, Universidade Estadual da Região Tocantina do Maranhão, jossi_agro@hotmail.com

${ }^{4}$ Engenharia Florestal, Universidade Estadual da Região Tocantina do Maranhão, diegoofreire@hotmail.com

5 Doutor em ciência do solo, Universidade Estadual da Região Tocantina do Maranhão, wilsonufrrj@yahoo.com.br
} 
das plantas, a indústria também reduziu o replantio, gerando outra economia. (BRUNHEROTO; TAKAHASHI, 2007).

\section{Fundamentação Teórica}

A Sociedade Brasileira de Silvicultura estima que, para atender a demanda de madeira em seus diversos setores, a necessidade de florestas plantadas deve chegar aos 630 mil hectares por ano, superando em muito os atuais 200 mil hectares plantados (SBS, 2006).

A demanda crescente por madeira, sendo bem superior à oferta regional, sugere a adoção de técnicas que propiciem alto rendimento das florestas. O preparo do solo para o plantio de espécies florestais visa disponibilizar água e nutrientes para o rápido estabelecimento das mudas. Apesar de técnicas menos intensivas de preparo serem preconizadas, há situações em que o preparo mais intensivo é necessário (GATTO et al., 2003), principalmente em situações de solos com alta compactação.

O presente estudo teve por objetivo avaliar a sobrevivência das mudas de eucalipto (Eucalyptus grandis) com e sem o uso de gel hidrorretentor na implantação da floresta, no município de Açailândia-MA e buscou responder as seguintes questões: $\mathrm{O}$ uso do gel hidrorretentor $(\mathrm{GH})$ interfere na sobrevivência das mudas aos cinco e trinta dias pós-plantio? O uso do GH na implantação da floresta apresenta viabilidade econômica (custo/benefício)?

\section{Metodologia}

Este estudo foi realizado em condições de campo, em uma área de reflorestamento situada na localidade de Açailândia-Ma. O solo da área foi classificado como LATOSSOLO Bruno/vermelho (LBEa1) (EMBRAPA, 1999).

O delineamento experimental foi em blocos inteiramente casualizados, composto de 2 tratamentos e 15 repetições, sendo cada repetição composta de 10 plantas (replicatas) dispostas em linha, totalizando 360 plantas da espécie Eucalyptus grandis. O plantio das mudas, procedentes do mesmo viveiro e semeadas na mesma data, foi realizado no mês de janeiro de 2007.

Os tratamentos foram compostos pelo método de plantio por coveamento, utilizandose o equipamento de perfuração mecânica Perfuradora Sthil BT120, abrindo-se covas de aproximadamente $30 \mathrm{~cm}$ de profundidade por $20 \mathrm{~cm}$ de diâmetro, onde as mudas foram transplantadas. Os tratamentos aplicados estão sumarizados na Tabela 1. 
Tabela 1. Modelo de distribuição dos Tratamentos. Fonte: Própria.

\begin{tabular}{c|cc|c}
\hline Tratamento & $\begin{array}{c}\text { Método de } \\
\text { Plantio }\end{array}$ & Gel Hidrorretentor & Sigla \\
\hline T1 (controle) & Coveamento & Sem Gel & CSG \\
T2 & Coveamento & Com Gel & CCG \\
\hline
\end{tabular}

No tratamento com gel foi utilizado o gel higroscópico de uso comercial, conforme recomendação do fabricante, sendo aplicados $250 \mathrm{ml}$ de solução por planta (solução elaborada com $3 \mathrm{~g}$ do produto para cada litro de água).

As mudas foram plantadas com espaçamento 2 x 2,5 (2 m entre plantas na linha e 2,5 $\mathrm{m}$ entre linhas). Em toda a área de bordadura do experimento foi utilizado um espaçamento de 2,5 m em relação ao restante da floresta, perfazendo uma área total de $1737,5 \mathrm{~m}^{2}$.

Uma análise não-paramétrica foi realizada para verificar a interferência do gel na viabilidade das plantas para os períodos de 5 e 30 dias após o plantio. Para análise da viabilidade econômica dos tratamentos, foram utilizados os custos por hectare para implantação de cada tratamento acrescido do custo de replantio (muda e mão de obra) sobre o $\%$ das mudas que não sobreviveram.

\section{Resultados e Discussão}

\section{Análise de Viabilidade aos 5 e 30 Dias do Plantio}

A viabilidade média das mudas aos 5 e 30 dias do plantio foi analisada, considerandose o efeito do tratamento com e sem GH. Observou-se que a viabilidade aos 5 dias do plantio foi significativamente superior $(\mathrm{p}<0,01)$ para os tratamentos com $\mathrm{GH}$ que obtiveram viabilidade média de $98,67 \%$, em relação aos tratamentos onde o $\mathrm{GH}$ não foi utilizado e a viabilidade média foi de 54,66\% (Tabela 2).

Estes dados validam as conclusões de Takahashi et al. (2004), que mostraram, em um experimento in vitro, uma melhor sobrevivência das mudas de eucalipto nos tratamentos com uso do GH até onze dias após o plantio, quando comparados com o tratamento controle sem GH. 
Quando comparadas as viabilidades das mudas aos 30 dias do plantio para o efeito dos tratamentos analisados, não se observou diferença significativa $(\mathrm{p}<0,05)$ referente ao uso ou não do GH nos tratamentos (Tabela 2).

É importante observar que na fase de implantação do experimento houve precipitação pluviométrica no local na semana que antecedeu o plantio, passando, posteriormente, por um período de estiagem de 23 dias pós-plantio.

Tabela 2. Média estimada das viabilidades aos 5 e 30 dias do plantio e níveis mínimos de significância para o efeito do GH no método de plantio em coveamento. Fonte: Própria.

\begin{tabular}{c|c|c|c}
\hline Tempo de Plantio & GH & $\begin{array}{c}\text { Viabilidade média } \\
\text { em \% }\end{array}$ & $\operatorname{Pr}>[\mathrm{t}]$ \\
\hline 05 dias & Não & 54,66 & $<0,0001$ \\
& Sim & 98,67 & 0,2036 \\
\hline 30 dias & Não & 22,66 & \\
& Sim & 16,00 &
\end{tabular}

* valores $<0,01$, são considerados como diferença significativa entre os tratamentos no bloco $(\mathrm{p}<0,01)$.

Estes dados divergem dos resultados apresentados por Dranski et al. (2009), em experimento com Pinhão-Manso no oeste do Paraná, no qual foi observado efeito significativo nos tratamentos secundários para a variável porcentagem de sobrevivência aos 90 dias do plantio, ao nível de $95 \%$ de probabilidade, onde plantas que sofreram a imersão em hidrogel obtiveram $95,56 \%$ de sobrevivência se comparado com 88,89\% de sobrevivência sem a imersão no hidrogel.

Sarvas et al. (2007) trabalharam com os efeitos do uso do hidrogel na sobrevivência e crescimento de Pinus sylvestris L. nas condições edafoclimáticas de Pieskovna/Eslováquia e resultados semelhantes foram observados pelos autores, que após um ano de crescimento vegetativo, verificaram que as mudas plantadas com a adição de hidrogel apresentaram sobrevivência entre $14 \%$ e $19 \%$ maior que o controle sem uso do hidrogel. Entretanto, não foram apresentados dados pluviométricos durante o período desses experimentos, o que dificulta a comparação com os dados do presente estudo.

\section{Análise de Viabilidade Econômica}

Para a análise da viabilidade econômica levou-se em consideração o custo de implantação da floresta por hectare, incluindo custo da muda, da mão de obra para plantio, 
dos tratos culturais, do herbicida e formicida no caso do tratamento testemunha, acrescentando-se o custo do GH para o tratamento teste e acrescentando-se como custo de replantio o custo da muda e da mão de obra de plantio em função do \% de mudas que não sobreviveram após os 5 dias do plantio (Tabela 3).

O uso do GH mostrou ser viável economicamente considerando o \% de sobrevivência das mudas, observado no experimento. Tendo como parâmetro o custo base de $\mathrm{R} \$$ $2.480,00 /$ ha, o custo com o uso do GH após o replantio das mudas mostrou ser 10,91\% menor que o custo para o plantio sem gel.

Tabela 3. Demonstrativo de viabilidade econômica em função do custo de plantio das mudas considerando os custos do replantio das mudas que não sobreviveram. Fonte: Própria.

\begin{tabular}{|c|c|c|c|c|c|}
\hline Tratamento & $\begin{array}{c}\text { Custo } \\
\mathrm{R} \$ / \mathrm{ha}\end{array}$ & $\begin{array}{c}\% \\
\text { replantio }\end{array}$ & $\begin{array}{c}\text { Custo de } \\
\text { replantio }\end{array}$ & $\begin{array}{c}\text { Custo total } \\
/ \text { ha }\end{array}$ & $\begin{array}{c}\text { Diferança sobre } \\
\text { o custo base }\end{array}$ \\
\hline $\mathrm{T} 1$ & $2.480,00$ & 45,34 & 357,05 & $2.837,05$ & 357,05 \\
\hline $\mathrm{T} 2$ & $2.555,00$ & 1,33 & 11,47 & $2.566,47$ & $86,47(-10,91 \%)$ \\
\hline
\end{tabular}

\section{Conclusões}

$\mathrm{O}$ efeito do uso de $\mathrm{GH}$ afetou positivamente e significativamente a viabilidade das mudas aos 5 dias do plantio, sendo que esta diferença não foi observada aos 30 dias do plantio para o experimento com período de 23 dias de estiagem após o plantio das mudas. O custo do plantio por hectare para o uso do GH mostrou ser 10,91\% menor quando considerado o custo de replantio das mudas que não sobreviveram após o quinto dia do plantio.

Os dados sugerem que o uso do GH pode melhorar a viabilidade das mudas na fase de plantio, seguida de períodos curtos de estiagem de, aproximadamente, dez dias. Desta forma pode-se supor que onde se utiliza sistemas de irrigação, o intervalo entre uma irrigação e outra pode ser aumentado, reduzindo o consumo de água e, consequentemente, os custos na implantação da floresta.

A busca e o estudo de novas técnicas que melhorem os rendimentos na produção de energia renovável, como se observa nas florestas plantadas, deve ser uma constante.

\section{Referências}

BRUNHEROTO, V. TAKAHASHI, S. Sistema de Plantio com Gel. International Paper do Brasil (IP), $2007 . \quad$ Disponível em http://www.celuloseonline.com.br/colunista/colunista.asp?IDAssuntoMateria=535\&iditem. Acesso em 08 de setembro de 2018. 
DRANSKI, J. A. L. PINTO JUNIOR, A. S. AJALA, M. C. AQUINO, N. F. MALAVASI, U. C. Efeito do uso de hidrogel na implantação e desenvolvimento de pinhão - manso no oeste do Paraná. In: I SEMINÁRIO INTERNACIONAL DE CIÊNCIA, TECNOLOGIA E AMBIENTE, 4, 2009. Cascavel: Anais... Cascavel: UNIOESTE, 28 a 30 de abril de 2009.

EMPRAPA, Mapa de solo do estado de Santa Catarina. 1999. Disponível em: http://mapserver.cnps.embrapa.br/website/pub/Santa_Catarina/viewer.htm. Acesso em 08 de setembro de 2018.

EMBRAPA - CNPSA. 2009. Disponível em: http://www.cnpsa.embrapa.br/sgc/ FCKeditor/editor/cotacao/ LSPS dados_estado_federacao.pdf. Acesso em 24 de julho de 2009.

FAGERIA, N.K. Otimização da eficiência nutricional na produção das culturas. Revista Brasileira Engenharia Agrícola. Ambiental, v.2, p.6 -16, 1998.

GATTO, A. BARROS, N. F. NOVAIS, R. F. COSTA, L. M. NEVES, J. C. L. Efeito do método de preparo do solo, em áreas de reforma, nas suas características, na composição mineral e na produtividade de plantações de Eucalyptus gandis. Revista Árvore. Viçosa MG, v.27, n.5, p.635-646, 2003.

MEDRADO, M.J.S. Cultivo do Eucalipto. EMBRAPA, 2003. Disponível em http://www.sistemasdeproducao.cnptia.embrapa.br. Acesso em 10 de setembro de 2018.

RIZZI, M. Plantio de Eucalipto com gel reduz consumo de água. Valor Econômico. Adaptado por Celulose Online, 2007. Disponível em http://www.cgimoveis.com.br/tecnologia/plantio-de-eucalipto-com-gel-reduz-consumo-deagua. Acesso em 10 de setembro de 2018.

SARVAS, M.; PAVLENDA, P.; TAKÁCOVÁ, E. Efeito da aplicação de hidrogel na sobrevivência e crescimento de plântulas de pinus em recriações. Journal of Forest Science, v.5, n. 53, p. 204-209, 2007.

SOCIEDADE BRASILEIRA DE SILVICULTURA - SBS. Estatísticas. Disponível em http://www.sbs.org.br. Acesso em 12 de outubro de 2018.

TAKAHASHI, E. N. SILVA, A. C. VALlE, C. F. RANGEL, T. M. CAVALCANTE, P. O. Uso de indicadores fisiológicos para avaliação do uso de gel hidroretentor de água em mudas clonais de Eucalyptus. UNESP, Jaboticabal. Disponível em http://www.rragrofloestal.com.br. Acesso em 13 de setembro de 2018. 